\title{
Aa. Vv., Les littératures européennes et les mythologies lointaines
}

Gabriella Bosco

\section{OpenEdition}

1 Journals

\section{Edizione digitale}

URL: https://journals.openedition.org/studifrancesi/26978

DOI: 10.4000/studifrancesi.26978

ISSN: 2421-5856

\section{Editore}

Rosenberg \& Sellier

\section{Edizione cartacea}

Data di pubblicazione: 1 avril 2007

Paginazione: 226-227

ISSN: 0039-2944

\section{Notizia bibliografica digitale}

Gabriella Bosco, «Aa. Vv., Les littératures européennes et les mythologies lointaines», Studi Francesi

[Online], 151 (LI | I) | 2007, online dal 30 novembre 2015, consultato il 23 novembre 2021. URL: http:// journals.openedition.org/studifrancesi/26978; DOI: https://doi.org/10.4000/studifrancesi.26978

Questo documento è stato generato automaticamente il 23 novembre 2021.

\section{(c) (i) (9)}

Studi Francesi è distribuita con Licenza Creative Commons Attribuzione - Non commerciale - Non opere derivate 4.0 Internazionale. 


\title{
Aa. Vv., Les littératures européennes et les mythologies lointaines
}

\author{
Gabriella Bosco
}

\section{NOTIZIA}

AA. VV., Les littératures européennes et les mythologies lointaines, textes réunis par

Véronique GÉLY, Jean-Marc MOURA, Joëlle PRUNGNAUD et Evanghélia STEAD, Editions du Conseil Scientifique de l'Université Charles-de-Gaulle Lille 3, 2006, pp. 297.

1 Il volume, che nasce dai lavori di un convegno dedicato all'argomento, si interroga sull'esistenza di un "esotismo mitologico", ovvero sul percorso inverso rispetto a quello per cui, tradizionalmente, la cultura europea ha imposto alle altre i propri miti di provenienza classica. Gli scrittori europei, infatti, hanno spesso raccontato miti e leggende importati da paesi lontani, nordici, meridionali o orientali: gli studi raccolti in questa miscellanea si chiedono in che modo questa importazione sia avvenuta. Il tema è affrontato secondo due punti di vista, quello dell'inventio e quello dell'elocutio: qual è stata cioè l'elaborazione europea della "materia esotica" e quali i miti privilegiati in primo luogo; in secondo luogo in che modo è stata proposta ai lettori europei una mitologia a loro sconosciuta.

2 Il fascino provato da molti autori di fine Ottocento per le mitologie lontane (basti citare Loti e Segalen, Kipling e Conrad) nasceva dalla constatazione che a differenza dell' Occidente in lutto per la morte dei suoi dei, altre popolazioni vivevano ancora della fiducia nei loro. Ma la traduzione occidentale di quei miti non è stata sempre fedele. Il pericolo maggiore è stato quello di far corrispondere l'universo mitologico dell'altrove esotico a un linguaggio infantile, ingenuo, desueto, indice di mentalità sentite come non civilizzate. Tendenza dominante cioè è stata quella di codificare l'alterità in base a modalità generali e antagoniste quali l'idealizzazione e la caricatura. Ma si è verificata anche, in certi casi, una diversa procedura, quella che ha permesso l'approccio al mito 
esotico come fondatore e portatore di una singolarità culturale, chiave d'accesso a una verità da scoprire al fine di poterla integrare.

Piuttosto che in base alla provenienza geografica di miti e leggende importate, $i$ curatori del volume hanno preferito seguire un criterio di ordine cronologico, all'interno di quattro modalità d'importazione: "Réceptions", "Acclimatations", "Réécritures", "Réinvestissement poétique et définition de soi".

4 La prima sezione raccoglie gli studi di Véronique GéLY su Les "autres mythologies" des mythographes: syncrétisme, comparatisme, curiosité poétique; di Muriel DÉTRIE su La réception occidentale des mythes de fondation du Japon; di Marie-Madeleine CASTELlani, Aux sources médiévales du mythe de l'homme du désert; e di Claudine LE BLANC, L'Inde à l'aune romantique. La seconde vie du mythe de Sacountalã dans la littérature française du XIX siècle.

5 La serie delle "Acclimatations" comprende gli studi di Sylvie BALLESTRA-PUECH, 'L'araignée sacrée': quelques jalons dans la réception occidentale d'une métaphore védique; di Fiona MCINTOSH-VARJABÉDIAN su Désymbolisation et resymbolisation du mythe oriental au XVIII siècle: quand la religion devient elle-même un mythe; di Evanghélia STEAD, La nouvelle Schéhérazade, la machine fiction et la lecture croisée: Théophile Gautier, Edgar Allan Poe et Nicolae Davidescu; di Joëlle PRUNGNAUD, Hiram: un mythe d'architecte au XIXe siècle; di Lucile ARNOUX-FARNOUX, Deux écrivains grecs devant l'Inde ancienne: Lorenzo Mavilis (s1860-1912) et Constantin Théotokis (1872-1923); di Philippe POSTEL, Les trois romans de Wang-loun ou l'exotisme d'Alfred Döblin dans son 'roman chinois'; e di Marjan KRAFFT-GROOT su La mythologie de l'Insulinde dans 'Les mille choses' de Maria Dermoût.

Nell'ambito poi delle "Réécritures", troviamo raccolti i contributi di Valeria BERTOLUCCIPIZzoRusso su "Les merveilles inquiétantes. Réception et métamorphose de l'oeuvre de Marco Polo dans les rifacimenti de Victor Chklovski et de Italo Calvino"; di Anna Maria BABBI, "Le dernier avatar de Pierre de Provence et la Belle Maguelonne: Der Busant. Von Trinkern, Polizisten und der schönen Maguelone de Peter Bichsel"; di Margaret SIRONVAL, "Ecritures européennes du conte d'Aladin et de la lampe merveilleuse"; di Bernard HUE, "De Maya à Amaterasu. Réécriture claudélienne de mythes orientaux"; e di AnneRachel HERMETET, "Egypte 1930: présence des dieux antiques dans les récits de voyage de Marinetti et d'Ungaretti".

7 Infine, nella sezione dedicata alle letture più dall'interno, "Réinvestissement poétique et définition de soi", figurano gli articoli di Anne томіснE, "Le Kha des Embaumés d'Egypte: statut et fonction de la mythologie egyptienne chez Artaud et Khlebnikov"; di Marie-Victoire NANTET su "L'usage claudélien du vase chinois"; di Marc KOBER su "L'acte gratuit de Lafcadio Hearn (les légendes et le folklore nippons vus par un écrivain apatride)"; di Philippe ANTOINE, "Chimérique Amérique: les nouveaux mondes de Chateaubriand"; di Olivier PENOT-LACASSAGNE su "Antonin Artaud, le dernier Tarahumara"; e di Anne LARUE su "L'Afrique au temps de Raymond Roussel".

8 Chiude il volume un indispensabile Index nominum che include i personaggi storici, quelli mitologici e mitici e le divinità. 